7. Reprod. Fert. (1970) 23, 79-85

\title{
THE SECRETION OF FLUID BY THE TESTES OF RATS, RAMS AND GOATS WITH SOME OBSERVATIONS ON THE EFFECT OF AGE, CRYPTORCHIDISM AND HYPOPHYSECTOMY
}

\author{
B. P. SETCHELL* \\ CSIRO Division of Animal Physiology, \\ The Ian Clunies Ross Animal Research Laboratory, N.S.W., Australia
}

(Received 29th September 1969)

\begin{abstract}
Summary. Fluid secretion by the seminiferous tubules of the testes of rats, rams and goats has been calculated from measurements of weight and water content of the testes after ligation of the efferent ducts. Measurement of fluid secretion made in this way gave similar results to other studies where the volume of fluid flowing from a catheter in the rete testis was measured. Fluid secretion was absent in the testes of very young animals but had reached adult proportions before the first spermatozoa were shed. Surgically-induced cryptorchidism and hypophysectomy in rats had no immediate effect on fluid secretion. Hypophysectomy in rats 1 to 4 weeks before efferent duct ligation caused a reduction in fluid secretion, but this fluid secretion was the same as that by control testes of the same weight. Cryptorchidism of 2 to 7 days' duration led to a decrease in fluid secretion. The ionic composition of fluid secreted by the testis was calculated and found to be similar to that of fluid collected from a catheter.
\end{abstract}

\section{INTRODUCTION}

It has been known for many years that ligation of the efferent ducts leading from the testis to the epididymis results in retention of the fluid which the testis secretes. The testis becomes distended and turgid, leading ultimately to degeneration of the germinal epithelium (see Waites \& Setchell, 1969, for references). Since a technique was developed for implanting a catheter to collect the fluid flowing from the rete testis of conscious rams (Voglmayr, Waites \& Setchell, 1966; Voglmayr, Scott, Setchell \& Waites, 1967), it has been possible to measure many features of the secretion of this fluid by the testis (see Setchell, Scott, Voglmayr \& Waites, 1969).

Because of the possibility that the implantation of a catheter might affect fluid secretion, it seemed desirable to devise an independent method of measuring fluid secretion by the testis. Measurement of the changes occurring after

* Present address: A.R.C. Institute of Animal Physiology, Babraham, Cambridge. 
efferent duct ligation (EDL) would appear to fulfil this need, at the same time providing a technique which could be applied to species with testes too small to cannulate.

\section{MATERIALS AND METHODS}

Rats

Wistar strain rats of various ages were used. They were anaesthetized with ether and one testis was delivered through an incision in the abdominal wall. The efferent ducts were ligated close to the testis and cut on the epididymal side of the ligature. The testis was then returned to the scrotum and the abdominal muscle and skin incisions were closed.

At various times after this first operation, the rats were again anaesthetized with ether, and both testes removed, weighed and dried at $104^{\circ} \mathrm{C}$ for $24 \mathrm{hr}$. Sometimes, a sample was first taken for histology. The dried testis was subsequently reweighed and $10 \mathrm{ml} 0 \cdot 1 \mathrm{~N}-\mathrm{HNO}_{3}$ was added to the dried testis to extract the $\mathrm{Na}, \mathrm{K}$ and $\mathrm{Cl}$ (Whittam, 1955). The testes of some rats were made cryptorchid by opening the scrotum, returning the testes to the abdomen and suturing the inguinal canals. The pituitaries of other rats were removed by the parapharyngeal approach. The completeness of hypophysectomy was checked by examining serial sections of the sella turcica. As an additional control, a portion of the mesorchium adjacent to the efferent ducts was ligated and cut in twenty rats, but no differences in weight or water content between ligated and control testes were found.

\section{Rams and goats}

Fourteen mature Merino rams 2 to 3 years old, twenty immature Dorset Down-Merino cross ram lambs between 1 and 7 months old, and eight mature Saanen billy-goats about 18 months old were used. Anaesthesia was induced with intravenous pentobarbitone sodium and maintained with fluothane. The scrotal skin was incised over the head of the epididymis, which was reflected to reveal the efferent ducts. The ducts were ligated and then cauterized on the epididymal side of the ligature. The animals were anaesthetized again at predetermined times, the testes removed, weighed and dried.

\section{Analytical techniques}

Sodium and potassium in the acid extracts were determined with the flame photometer attachment of an autoanalyser (Technicon, Chaucey, New York). Chloride was determined by the autoanalyser method with mercuric thiocyanate, ferric nitrate and mercuric nitrate or with a coulometric chloride meter (Evans Electroselenium Limited, Halstead, Essex).

\section{Histological techniques}

Tissue for histological examination was fixed in Susa fluid and embedded in paraffin. Sections were cut $7 \mu$ thick and stained with Feulgen and alcian blue or Weigert's iron haematoxylin.

\section{Calculation of results}

The weight and water content of the ligated testes were compared with the contralateral, unligated, control testes and the results are expressed as the ratio 
of ligated to control testes (EDL/control ratio). Water content of the control, adult rat testes was $6.70 \pm 0.023$ (S.E. of mean) $\mathrm{g}$ water/g dry tissue (118 observations), $6 \cdot 40 \pm 0.44 \mathrm{~g} / \mathrm{g} \mathrm{(6)}$ for the ram testes and $6 \cdot 27 \pm 0 \cdot 15 \mathrm{~g} / \mathrm{g}(6)$ for the goat testes.

\section{Mature animals}

\section{RESULTS}

In all the sexually mature animals, weight and water content of the testes increased after efferent duct ligation. In unilaterally ligated animals, the increase was linear for about $30 \mathrm{hr}$ in young rats $(60$ to 70 days old, 100 to

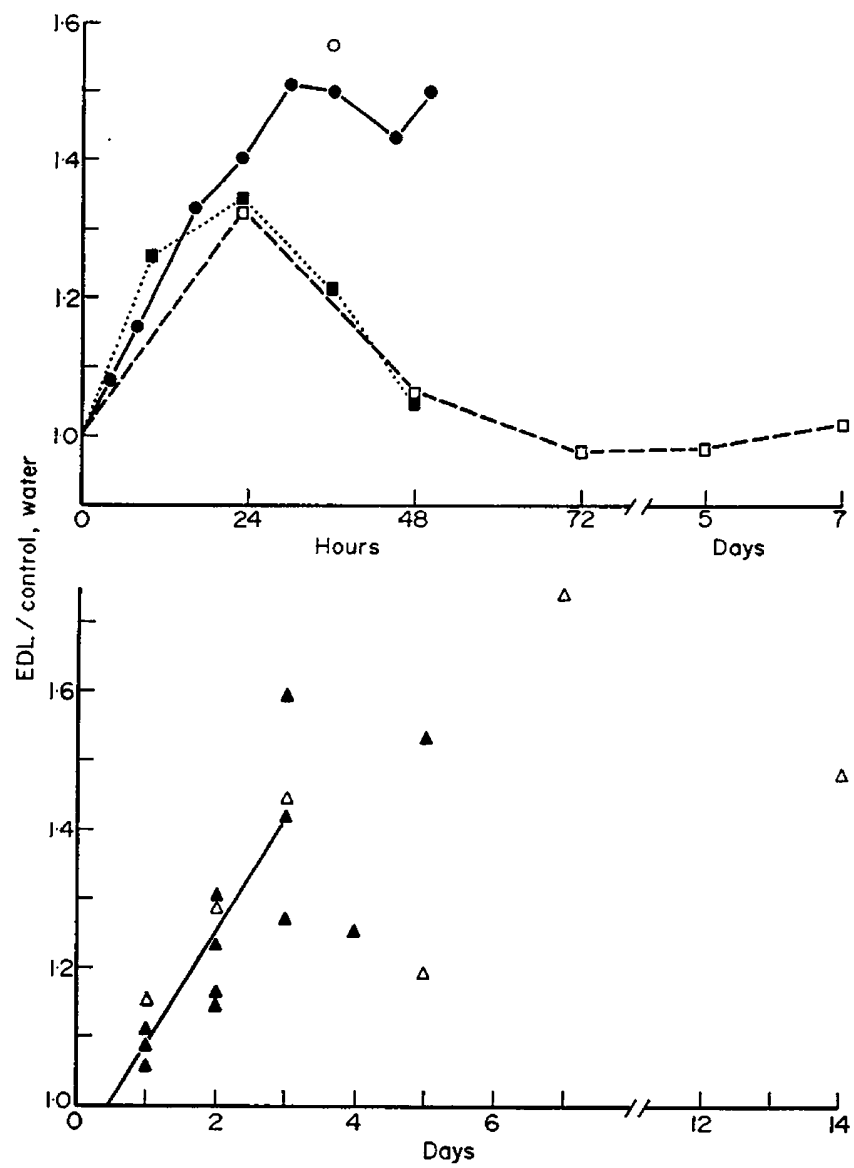

TEXr-rIG. 1. The ratio of the water contents ( $g$ water/g dry weight) of testes with EDL to the contralateral control testes, or with bilateral EDL to the mean value for control testes of similar animals. Rats 100 to $150 \mathrm{~g}$ : unilateral EDL (๑), bilateral EDL (O); rats

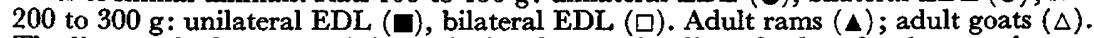
The line on the lower graph is a calculated regression line of values for sheep and goats for between 1 and 3 days inclusive after EDL.

$150 \mathrm{~g}$ ) about $24 \mathrm{hr}$ in older rats (90 to 120 days old, 200 to $300 \mathrm{~g}$ ) and $72 \mathrm{hr}$ in goats and rams (Text-fig. 1). Thereafter, the weight and water content remained high or decreased and there was progressive degeneration of the seminiferous epithelium. Both the internal and external diameters of the 
seminiferous tubules of rats were increased $24 \mathrm{hr}$ after EDL by $55 \pm 3 \%$ and $6 \pm 1 \%$ respectively from control values of $84 \pm 2 \mu$ and $206 \pm 4 \mu$ respectively. There was little apparent change in the interstitial tissue. The maximal EDL/ control ratios for weight and water content were slightly less in older rats than in 60-day rats, possibly because the greater amount of fibrous tissue restricted the fluid accumulation (Text-fig. 2). The rate of weight gain, and hence of

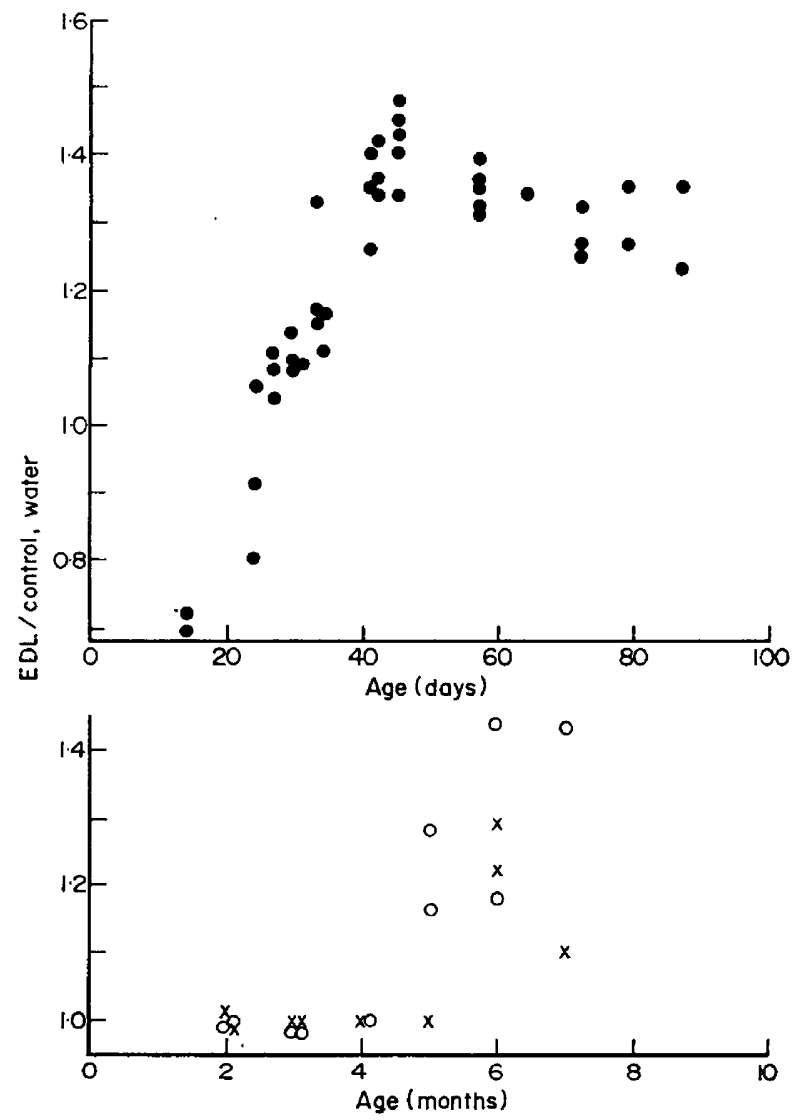

Texr-FiG. 2. Fluid secretion, measured by the ratio of the water content ( $g$ water/g dry weight) of testes with EDL to contralateral control testes, in rats $(-24 \mathrm{hr}$ after EDL) and ram lambs $(x=24 \mathrm{hr}$ after EDL, $O=48 \mathrm{hr}$ after EDL).

fluid secretion, was $1.0 \mathrm{~g} / 100 \mathrm{~g} / \mathrm{hr}$ in rams and goats, and $2.2 \mathrm{~g} / 100 \mathrm{~g} / \mathrm{hr}$ in rats.

\section{Immature animals}

No fluid was secreted by the testes of rats younger than 30 days; in fact, EDL appeared in some instances to cause a decrease in weight and water content in the smallest testes. Fluid secretion in rats was maximal by 45 days, and there was less variation in fluid secretion between rats of the same weight than between rats of the same age. In the young rams, there was no fluid secretion until 5 months of age; in older animals, fluid secretion approached that in adult animals (Text-fig. 2). 
Control

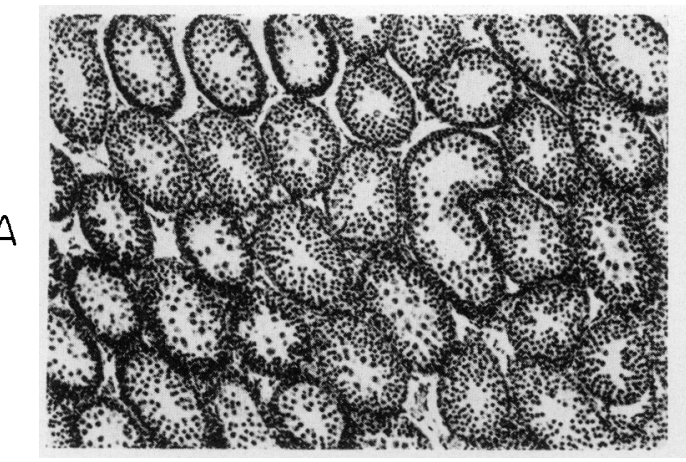

EDL

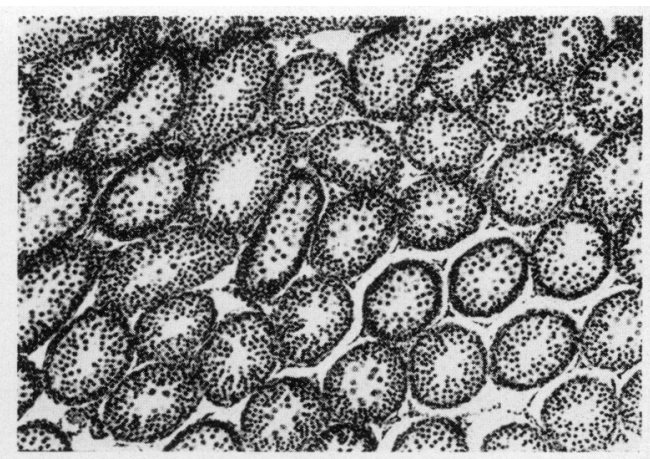

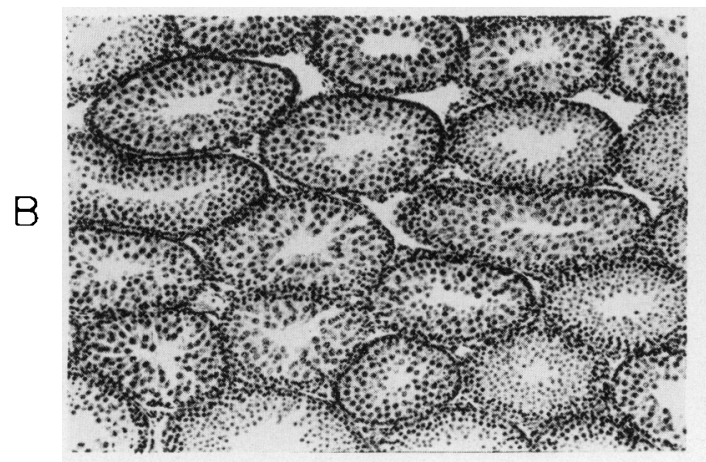
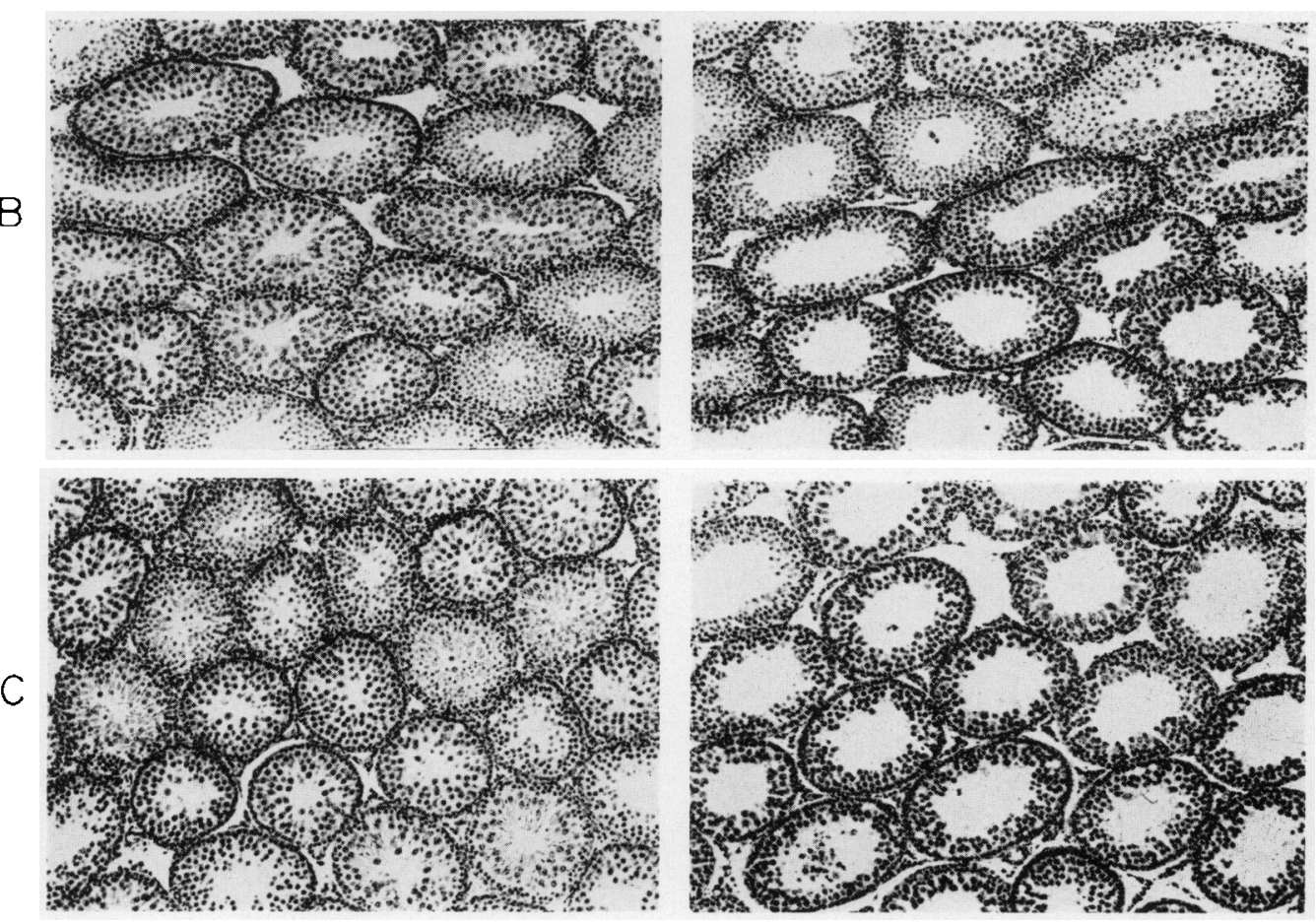

$1 \mathrm{~mm}$

Sertions of eontrol and ligated testes (ki)t of rats of various ages

1. Rat 24 days old, no fluid secretion. EDL/control water content after $24 \mathrm{hr}, 0.91$.

13. Rat 33 days old, fluid secretion beginning, EDL/control water content. 1/17.

(: Rat 4.1 davs old. Iluid secretion maximal. EI)L/control water ontent. 1935. 


\section{Control}
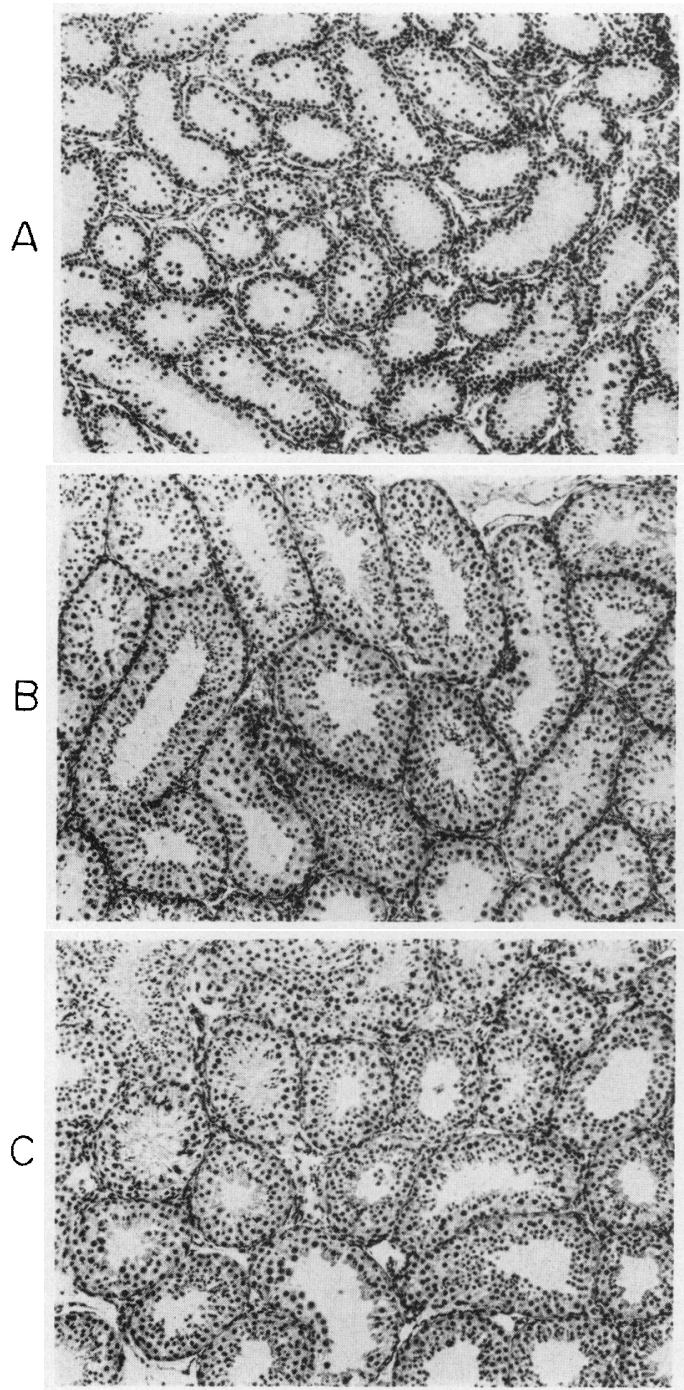

EDL
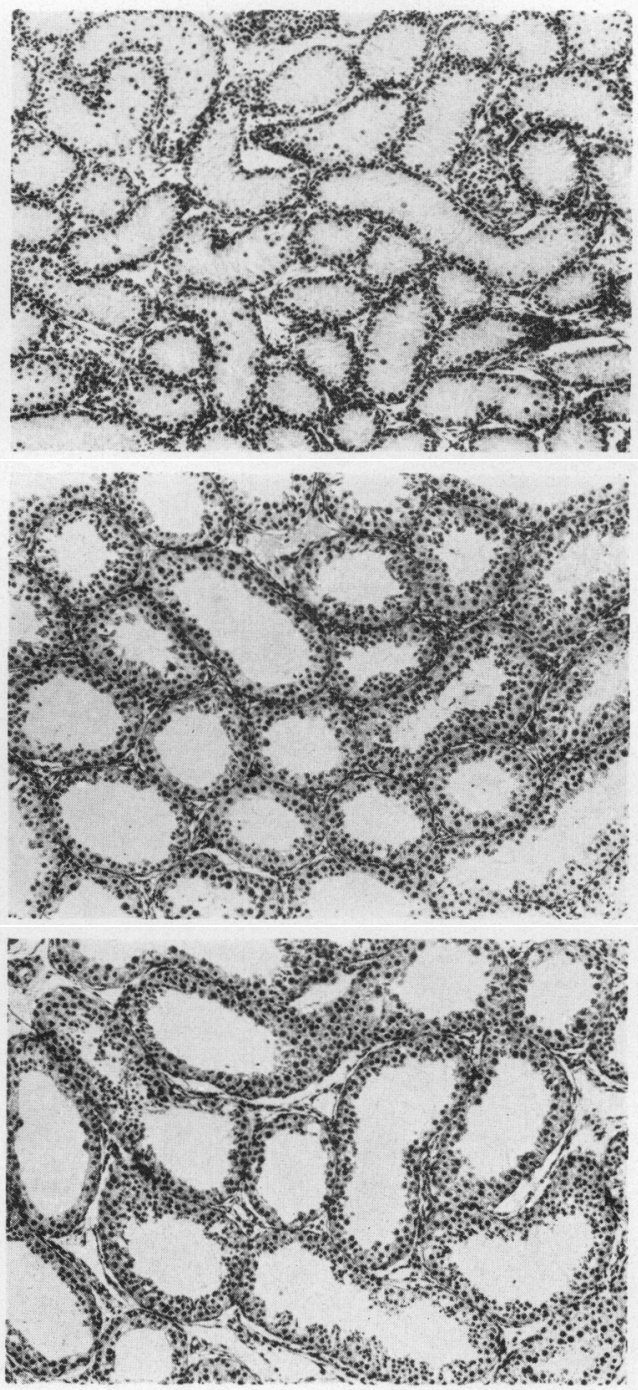

$\mathrm{I} \mathrm{mm}$

Sections of control and t8-hr ligated testes (l:1)l of ram lambs of various ages.

1. Ram 4 months old. no fluid secreted. EDl icontrol water content, 1+00.

B. Ram 5 months old. fluid secretion beginning, libl/control water content, $1 \cdot 16$.

( $\therefore$ Ram 5 months old. fluid secretion at adult rates, EI)I./control water content. 1.28. 
In the rat, the beginning of fluid secretion coincided with the appearance of the first spermatids and had reached maximal rates before the first spermatozoa were shed (Plate 1). In the ram lambs, some spermatozoa could be found in the smallest testes secreting fluid, but the ram lambs formed a less complete series than the rats. Nevertheless, fluid secretion was maximal before full spermatogenesis had begun (Plate 2).

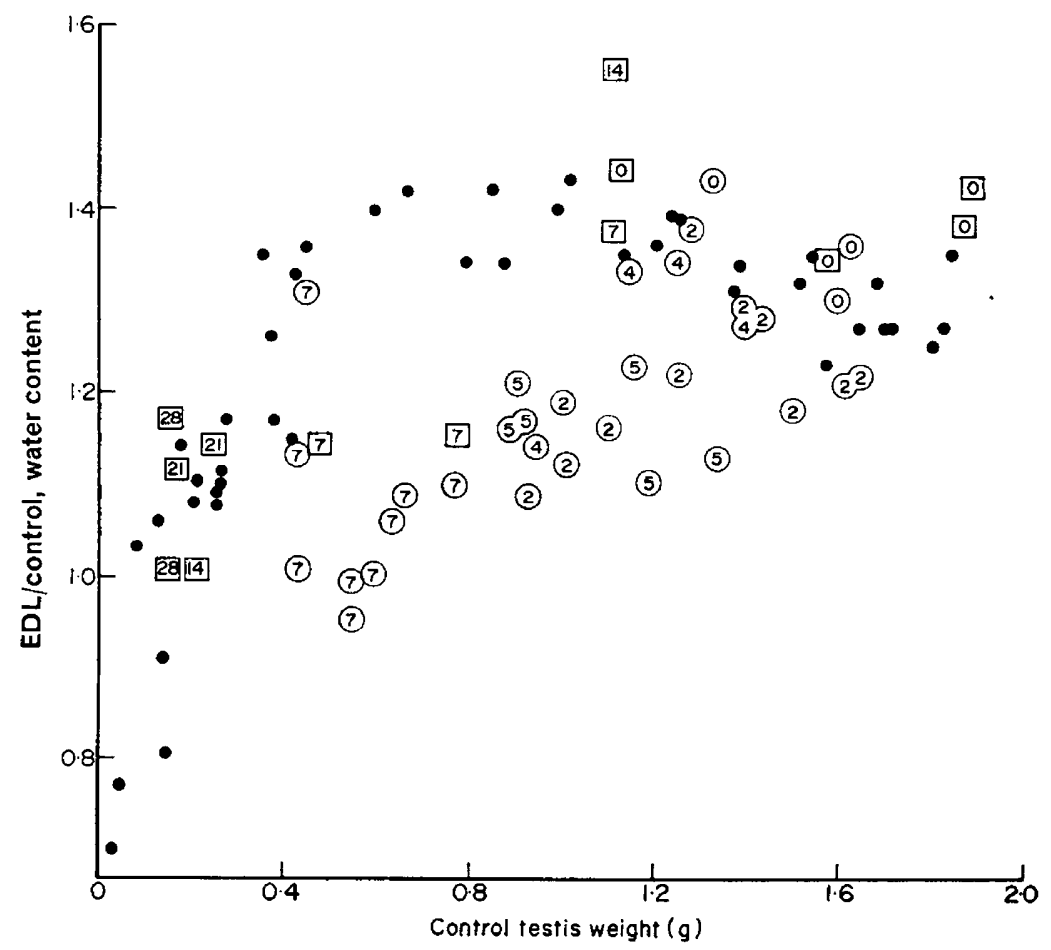

TEXT-FIG. 3. Fluid secretion measured by the ratio of water content (g water/g dry weight) of testes with EDL for $24 \mathrm{hr}$ to contralateral control testes, of normal rats of different ages $(\bullet)$, cryptorchid rats $(O)$ and hypophysectomized rats $(\square)$. The number in the hollow symbols is the number of days before EDL that the rats were hypophysectomized or made bilaterally cryptorchid. These data are plotted against testis weight rather than body weight or age because both the cryptorchid testes and the testes of hypophysectomized rats were smaller than testes of control rats of the same age and body weight.

\section{Ionic composition of fluid secreted}

In order to calculate the composition of the fluid secreted by the testes, it must be assumed that the composition of the cellular part of the testis is not affected by EDL during the period of linear increase in weight. Then, if the total ionic content of the control testis is subtracted from that of the ligated testis, and the resultant value divided by the difference between the two testes in the amount of water content, values are obtained for the concentrations of ions in the secreted fluid. In the fluid secreted by rat testes, sodium was appreciably less and potassium and chloride more than in plasma; $134 \pm 2 \cdot 1$ m-equiv./litre (mean \pm S.E. of mean, 36 observations), $17.0 \pm 2.90$ and $137 \pm 4.0$ compared with $146 \pm 0.86(6), 3 \cdot 68 \pm 0.22$ and $110 \pm 0.82$ respectively. 
Fluid secretion by cryptorchid testes of rats

Rat testes returned to the abdomen at the time of EDL secreted normal amounts of fluid, as did some of those which had been in the abdomen for 2 or 4 days. However, most of the testes which had been made cryptorchid for 5 or 7 days secreted less fluid than scrotal testes of the same weight (Text-fig. 3); the cryptorchid testes were smaller than scrotal testes of rats of the same age and body weight.

Fluid secretion by the testes of rats after hypophysectomy

Hypophysectomy of rats $24 \mathrm{hr}$ before EDL had no effect on fluid secretion but, at longer intervals after hypophysectomy, fluid secretion was reduced. However, the testes were also smaller in size than the testes of control rats of the same body weight. If fluid secretion by the testes of the hypophysectomized rats was compared with fluid secreted by control testes of the same weight from younger rats, no difference was apparent (Text-fig. 3 ).

\section{DISCUSSION}

This method of measuring fluid secretion by the testis yields results which compare very closely with those obtained by cannulating the rete testis of the ram (Voglmayr et al., 1966, 1967) and the goat (Setchell \& Linzell, unpublished). In the bull, the weight gain after EDL (Gustafsson, 1966) was similar to the rate of fluid secretion through a catheter in the rete testis (Voglmayr, Larsen \& White, 1970). The ionic composition of the fluid determined by the two techniques was also essentially similar. While it is not possible to determine the composition of the fluid obtained after EDL as accurately or as easily as that of fluid collected direct from a catheter, nevertheless the present method has several advantages for measuring fluid secretion. It should be applicable to a wider variety of species, particularly those with smaller testes and to animals of a much wider range of ages. Secondly, it is possible to be reasonably sure in the rat that, if there is no gain in weight or water content after EDL, then the testis has secreted no fluid. In measuring the output from a catheter, it is difficult to be sure that a fall in flow rate is not due to a partial or temporary obstruction of the catheter. The present technique would therefore seem particularly useful for studying the effects of possible inhibitors.

Barack (1968) used the weight gain of the mouse testis $24 \mathrm{hr}$ after EDL as a measure of fluid secretion but did not establish whether fluid accumulation was linear up to that time; his results show that it certainly was not after 48 and $72 \mathrm{hr}$. Nevertheless, these data are consistent with the present results regarding the long-term effects of cryptorchidism and hypophysectomy. The lack of short-term effects of both these treatments suggests that the processes involved in fluid secretion are not immediately sensitive to heat, nor do they depend directly on a normal concentration in the circulating blood of pituitary hormones. Because the testes do not enlarge when the efferent ducts are ligated in rats several days after cryptorchidism, 7 or more days after hypophysectomy and in immature animals, it would appear that the accumulation of fluid in 
normal, mature animals is a result of a specific process. Indeed, fluid secretion seems to be part of the function of the normal mature testis.

The histological changes after EDL of increased tubular diameter, particularly internal diameter, with no change in the interstitial tissue suggest that the fluid arises within the seminiferous tubules. From the experiments with the pubertal animals, it would appear that fluid secretion is not associated with the final stages of spermateleosis or sperm release, and thus fluid must be secreted by cells surrounding the seminiferous tubules, the earlier cells of the seminiferous epithelium or, more likely, by the Sertoli cells.

\section{ACKNOWLEDGMENTS}

I am grateful to N. T. Hinks, B. W. Brown and A. W. Reid for their assistance, to I. S. Wheatley for doing the hypophysectomies, and to Dr J. L. Linzell for his help with the experiments on the goats.

\section{REFERENCES}

Barack, B. M. (1968) Transport of spermatozoa from seminiferous tubules to epididymis in the mouse: a histological and quantitative study. F. Reprod. Fert. 16, 35.

Gustarsson, B. (1966) Luminal contents of the bovine epididymis under conditions of reduced spermatogenesis, luminal blockage and certain sperm abnormalities. Acta vet. scand. Suppl. 17.

Setchele, B. P., Scott, T. W., Voglmayr, J. K. \& Wattes, G. M. H. (1969) Characteristics of testicular spermatozoa and the fluid which transports them into the epididymis. Biol. Reprod. Suppl. 1, 40.

Voglmayr, J. K., Larsen, L. H. \& White, I. G. (1970) Metabolism of spermatozoa and composition of fluid collected from the rete testis of living bulls. 7. Reprod. Fert. 21, 449.

Vogzmayr, J. K., Scott, T. W., Setchell, B. P. \& Wartes, G. M. H. (1967) Metabolism of testicular spermatozoa and characteristics of testicular fluid collected from conscious rams. F. Reprod. Fert. 14, 87.

Voglmayr, J. K., Watres, G. M. H. \& Setchell, B. P. (1966) Studies of spermatozoa and fluid collected directly from the testis of the conscious ram. Nature, Lond. 210, 861.

Watres, G. M. H. \& SeTchell, B. P. (1969) Some physiological aspects of the function of the testis. In: The Gonads. Ed. K. W. McKerns. Appleton Century Crofts, New York.

Whittam, R. (1955) A convenient micro method for the estimation of tissue chloride. 7. Physiol., Lond. $128,65 \mathrm{P}$. 